\title{
THE GREENHOUSE EFFECT AND GLOBAL WARMING
}

Victoria Kubatko, Denys Smolennikov

Sumy State University, Sumy, Ukraine

Scientists predict that during global warming, the northern regions of the Northern Hemisphere will heat up more than other areas of the planet, northern and mountain glaciers will shrink, and less ice will float on northern oceans. Regions that now experience light winter snows may receive no snow at all. In temperate mountains, snowlines will be higher and snow packs will melt earlier. Growing seasons will be longer in some areas. Winter and night time temperatures will tend to raise more than summer and daytime ones.

The warmed world will be generally more humid as a result of more water evaporating from the oceans. Scientists are not sure whether a more humid atmosphere will encourage or discourage further warming. On the one hand, water vapour is a greenhouse gas, and its increased presence should add to the insulating effect. On the other hand, more vapour in the atmosphere will produce more clouds, which reflect sunlight back into space, which should slow the warming process.

Greater humidity will increase rainfall, on average, about 1 percent for each Fahrenheit degree of warming. (Rainfall over the continents has already increased by about 1 percent in the last 100 years.) Storms are expected to be more frequent and more intense. However, water will also evaporate more rapidly from soil, causing it to dry out faster between rains. Some regions might actually become drier than before. Winds will blow harder and perhaps in different patterns. Hurricanes, which gain their force from the evaporation of water, are likely to be more severe. Against the background of warming, some very cold periods will still occur. Weather patterns are expected to be less predictable and more extreme.

The total consumption of fossil fuels is increasing by about 1 percent per year. No steps currently being taken or under serious discussion will likely prevent global warming in the near future. The challenge today is managing the probable effects while taking steps to prevent detrimental climate changes in the future. Damage can be curbed locally in various ways. Coastlines can be armoured with dikes and barriers to block encroachments of the sea. Alternatively, governments can assist coastal populations in moving to higher ground. Some countries, such as the United States, still have the chance to help plant and animal species survive by preserving habitat corridors, strips of relatively undeveloped land running north and south. Species can gradually shift their ranges along these corridors, moving toward cooler habitats. There are two major approaches to slowing the build up of greenhouse gases. The first is to keep carbon dioxide out of the atmosphere by storing the gas or its carbon component somewhere else, a strategy called carbon sequestration. The second major approach is to reduce the production of greenhouse gases. For more than a century scientists have known that certain gases in the atmosphere - most notably water vapour, carbon dioxide, and methane - contribute to atmospheric warming. These greenhouse gases, which also include nitrous oxide and chlorofluorocarbons, allow about half of the short-wave radiation in sunlight to pass through the earth's atmosphere, heating the earth's surface. At the same time, greenhouse gases absorb and reradiate most of the longer wavelengths of radiation, such as infrared radiation, which is emitted by the earth's warmed surface. This heat-trapping capacity of the atmosphere is popularly known as the "greenhouse effect."

Despite public controversy surrounding global warming, the natural greenhouse effect has been long established as fact in the scientific community. Indeed, were it not for the heat-trapping action of clouds, water vapour, carbon dioxide, and other gases, the earth's natural climate would be about $33^{\circ} \mathrm{C}$ (about $60^{\circ} \mathrm{F}$ ) cooler than it is. Life would have evolved quite differently in such a climate.

Most scientists believe that the rapid expansion of agricultural and industrial activities over the last several hundred years have generated significant increases in carbon dioxide and methane in the atmosphere.

However, experts disagree about whether such changes have caused the increase of approximately $0,5^{\circ} \mathrm{C}\left(\right.$ about $1^{\circ}$ F) in the earth's surface temperature that has been documented over the past century.

Many scientists cite the fact that 1997 was the warmest year on record, following a decade in which 9 of the 11 hottest years this century were reported, as strong, but circumstantial, evidence that human activities have altered the earth's climate. Other experts, however, believe this temperature trend is a natural variation.

Also disputed is whether projected world population growth to more than 10 billion people by the year 2100 will result in a doubling or tripling of atmospheric concentrations of carbon dioxide. If such a build up occurs, as many scientists predict, global surface temperatures could increase by anywhere from about one Celsius degree (about two Fahrenheit degrees) to about four Celsius degrees (about seven Fahrenheit degrees) during the next century. The higher half of this range involves temperature changes outside of those experienced by human civilizations since the end of the last ice age some 10,000 years ago.

During the last ice age, average global temperatures were only about five Celsius degrees (about nine Fahrenheit degrees) cooler than the present period. The total consumption of fossil fuels is increasing by about 1 percent per year.

No steps currently being taken or under serious discussion will likely prevent global warming in the near future. The challenge today is managing the probable effects while taking steps to prevent detrimental climate changes in the future. Damage can be curbed locally in various ways. Coastlines can be armoured with dikes and barriers to block encroachments of the sea.

Alternatively, governments can assist coastal populations in moving to higher ground. Some countries, such as the United States, still have the chance to help plant and animal species survive by preserving habitat corridors, strips of relatively undeveloped land running north and south. Species can gradually shift their ranges along these corridors, moving toward cooler habitats. 
There are two major approaches to slowing the build up of greenhouse gases. The first is to keep carbon dioxide out of the atmosphere by storing the gas or its carbon component somewhere else, a strategy called carbon sequestration. The second major approach is to reduce the production of greenhouse gases. 